\title{
A long story begun with a simple sore throat
}

\author{
Giuseppina Pisano $\cdot$ Paola Bonara $\cdot$ Paolo Rietti $\cdot$ Lorena Airaghi $\cdot$ \\ Luigi Sinigaglia · Giovanni Boccoli $\cdot$ Larry Burdick • Marta del Medico • \\ Edoardo Pulixi · Fabio Silini · Alessandra Gandolfi · Silvia Fargion
}

Received: 11 June 2010/Accepted: 1 July 2010/Published online: 22 July 2010

(C) SIMI 2010

\section{Case presentation}

Dr. Bonara: A 30-year-old woman was admitted to our emergency department (ED). In the past history, she had prolonged estrogen-progestinic treatment. In April 1999, she was admitted to the Infectious Diseases Department at the Polyclinic in Messina for acute pericarditis (the episode resolved quickly, and the patient was discharged without any therapy). At the end of February 2009, she had a sore throat and fever unresponsive to nonsteroidal anti-inflammatory drugs (NSAIDS) and amoxicillin. On March 7, the patient came to the ED for the persistence of fever, and the onset of diffuse myalgias and sternal pain. The electrocardiogram showed sinus tachycardia, widespread ST elevation (Fig. 1); chemistries: troponin I $15.81 \mathrm{ng} / \mathrm{mL}(<0.15)$, AST $111 \mathrm{U} / \mathrm{L}$, ALT 32 U/L, CK 449 U/L, CRP 35 mg/dL, Hb 11.8 g/dL, Ht $30 \%$, MCV $86 \mathrm{fL}$, WBCs $21,120 / \mu \mathrm{L} \rightarrow$ neutrophils $91 \%$. The echocardiogram showed no alterations of the left ventricle (normal size, wall thickness and segmental contraction), EF 55\%, mild mitral regurgitation, no pericardial effusion; chest X-ray: normal.

G. Pisano $(\bowtie) \cdot$ P. Bonara · L. Airaghi · G. Boccoli ·

L. Burdick · M. del Medico - E. Pulixi · F. Silini .

A. Gandolfi - S. Fargion

Reparto Medicina Interna 1B, UO Dipartimento di Medicina

Interna, Università di Milano/Fondazione IRCCS

Cà Granda-Ospedale Maggiore Policlinico, Milan, Italy

e-mail: pinaz81@hotmail.com

P. Rietti

UO Cardiologia, Azienda Ospedaliera S. Carlo Borromeo,

Milan, Italy

L. Sinigaglia

Dipartimento di Reumatologia, Istituto Ortopedico G. Pini,

Milan, Italy
Dr. Rietti (cardiologist): Clinical presentation, blood tests, and electrocardiogram were suggestive for myopericarditis; the patient was then hospitalized at the Department of Cardiology.

During the hospitalization there was evidence of a pericardial effusion (measured by ultrasound: $8 \mathrm{~mm}$ in short axis view in diastole, Fig. 2) with dyskinesia of the interventricular septum and hypokinesia of the right ventricle, and the occurrence of a pleural effusion (first left and then bilateral); the presence of intermittent fever was confirmed. Blood tests showed marked neutrophilic leukocytosis (WBCs 20,000/ $\mu \mathrm{L}$, neutrophils 75\%) and increased acute-phase proteins (CRP $35 \mathrm{mg} / \mathrm{dL})$. Marked proteinuria $(1.66 \mathrm{~g} / \mathrm{dL})$ with hypoalbuminemia was also detected (albumin $1.4 \mathrm{~g} / \mathrm{dL}$ ). All investigations of infective and autoimmunity diseases were negative. The patient was treated with acetylsalicylic acid (2 g daily). On March 12, a nephrological consultation was requested because of persistent proteinuria and cylindruria.

Nephrologist: In this patient, the post-infectious nature or a systemic/immunologic disease with renal involvement cannot be excluded. We suggested the introduction of methylprednisolone $20 \mathrm{mg}$ daily, and to obtain an abdominal ultrasound study.

Dr. Rietti (cardiologist): Methylprednisolone $20 \mathrm{mg}$ daily was started and later increased to $40 \mathrm{mg}$ daily with broadspectrum antibiotics, i.e. vancomycin and ciprofloxacin. The abdominal ultrasound study was normal. The clinical picture at this point included fever with peaks up to $40^{\circ} \mathrm{C}$, intermittent episodes of precordial pain, and dyspnea. On March 14, the chest X-ray study showed a pleural effusion; the echocardiogram showed reduction of the known pericardial effusion. A worsening of the anemia and a decrease 


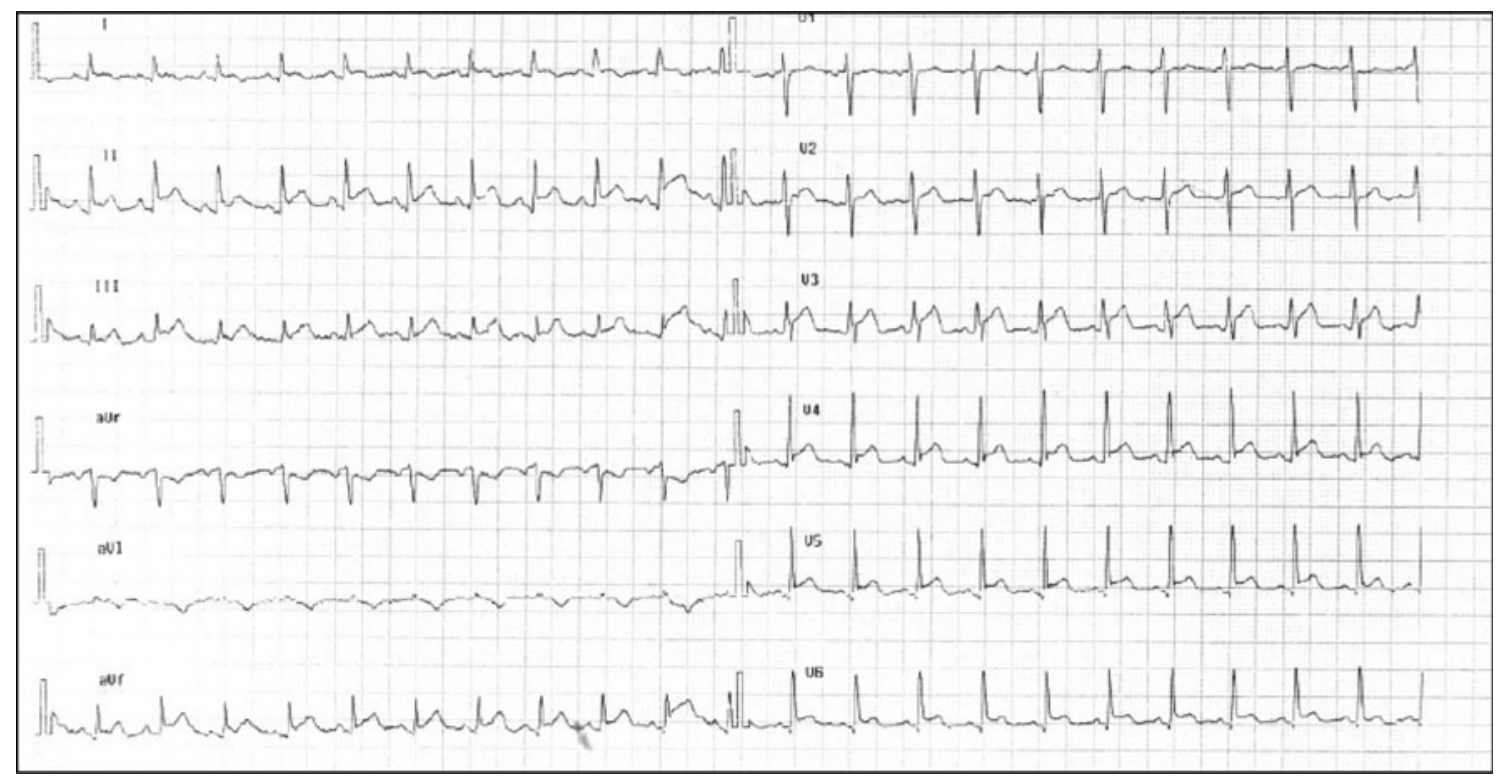

Fig. 1 Electrocardiogram: sinus tachycardia, widespread ST elevation

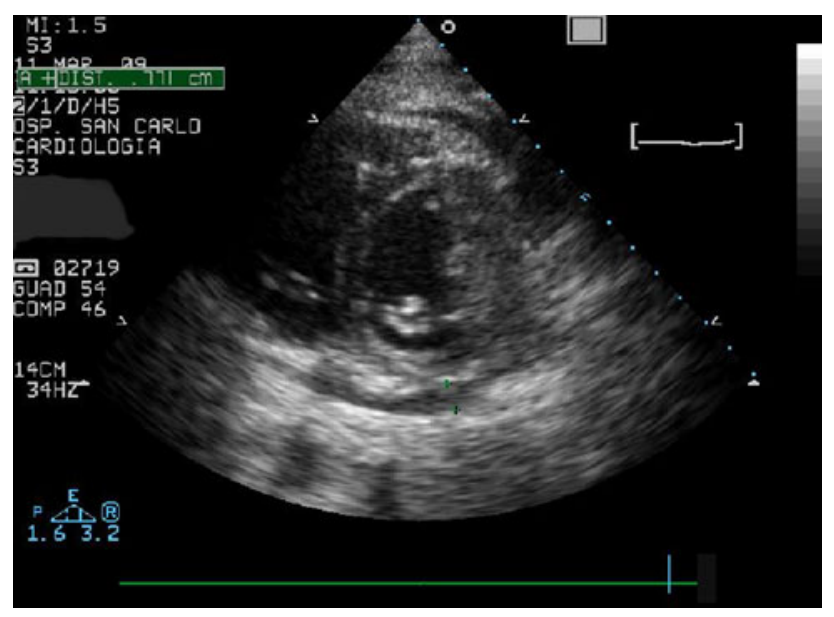

Fig. 2 Parasternal short axis, view of transthoracic echocardiogram. Pericardial effusion

in the platelet count were noted. The patient was then transferred to the Department of Internal Medicine of the Fondazione Policlinico University Hospital.

Dr. Airaghi: Upon admission, the patient was alert, oriented to time and place, cooperative and afebrile. She complained of chest pain. The respiratory rate was 40 breaths/min at rest, the oxygen saturation was $96 \%$ while breathing oxygen $(4 \mathrm{~L} / \mathrm{min})$; blood pressure and heart rate were 100/55 $\mathrm{mmHg}$ and 130 beats/min, respectively. Auscultation revealed a pericardial friction rub in the mesocardium. The breath sounds were barely audible at the middle-lower field of left lung. Jugular venous distension was present. The remaining physical examination was normal. Blood tests showed worsening of the anemia
(Hb $8.1 \mathrm{~g} / \mathrm{L}$, RBCs $2.9 \times 10^{6} / \mu \mathrm{L}$, Ht $25 \%$, MCV $87 \mathrm{fL}$, RDW 14\%) with leukocytosis (WBCs $14,200 / \mu \mathrm{L}$ ); normal renal function indexes and electrolytes; liver dysfunction (CHE 2,418 U/L, albumin $2.6 \mathrm{~g} / \mathrm{dL}$ ), bleeding disorders (PT 1.52, PTT 0.97, fibrinogen $303 \mathrm{mg} / \mathrm{dL}$, D-dimer 22,000 ng/dL); increased acute-phase proteins (CRP $16.8 \mathrm{mg} / \mathrm{dL}$, ferritin 12,868 ng/mL), LDH $1,045 \mathrm{U} / \mathrm{L}$; myocardial enzymes were normal. An echocardiogram showed a reduced pericardial effusion in comparison to the previous study. A chest X-ray study showed bilateral pleural effusions, greater on the right side (Fig. 3).

A left chest thoracostomy tube was inserted and a clear liquid with fibrin clots was drawn. Bacterial and mycobacterial cultures were negative. Given the failure of previous empirical antibiotic therapy, piperacillin/tazobactam was started.

Over the following days, a gradual increase of the bilateral pleural effusions was observed and a right thoracostomy was performed. Purpuric lesions of the upper limbs, abdomen and thighs were noted, which gradually reduced during the following days with complete spontaneous resolution. The patient presented also a progressive impairment of the blood counts, evidencing microcytic anemia ( $\mathrm{Hb} 8 \mathrm{~g} / \mathrm{dL}, \mathrm{Ht} 25 \%)$, leukopenia $(2,600 / \mu \mathrm{L})$, and thrombocytopenia $(100,000 / \mu \mathrm{L})$.

\section{Differential diagnosis}

Dr. Gandolfi, Dr. Pisano, Dr. Silini: The patient's clinical presentation suggested the presence of a multisystemic polyserositis disease. Infectious, cancer, and inflammatory diseases were all considered as part of the differential 


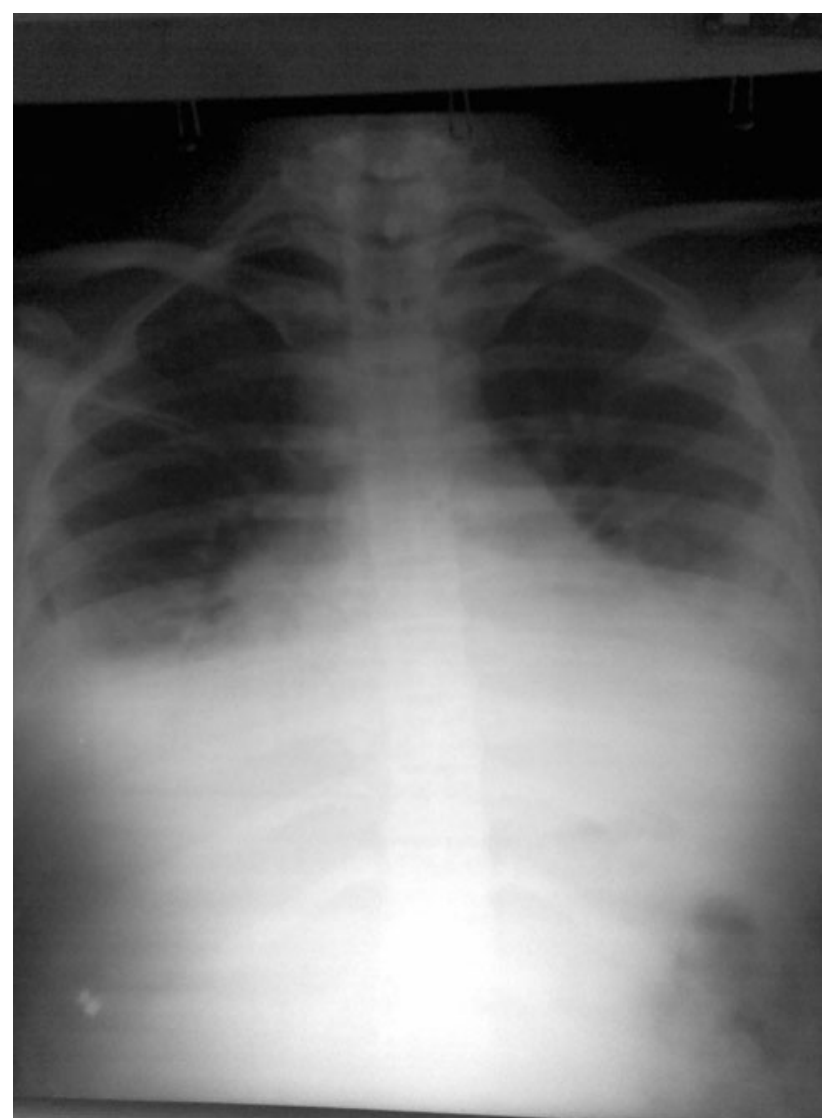

Fig. 3 Chest X-ray: bilateral pleural effusions, greater on the right side

diagnosis. With the sudden clinical onset, the presence of recurrent fever appeared less likely. Investigations aimed at finding infectious diseases of bacterial (sputum culture, blood cultures, swabs, culture of pleural fluid, urine culture, mycobacterial research) or viral origin (tests for rubella, CMV, EBV, Coxsackie, Borrelia, Chlamydia, HIV) were all negative. A contrast-enhanced computed tomography (CT scan) of the chest and abdomen excluded the presence of solid tumors, while the presence of an acute blood disease appeared unlikely in view of the normal peripheral blood smear. The genesis of the anemia was linked to an acute inflammation that was in progress, while the leucocytosis was probably reactive. During the hospitalization, there was also a transient leukopenia. Because of the possibility of an inflammatory disease of autoimmune origin, specific autoantibodies were sought (ANA, ENA screening, ANCA, rheumatoid factor, anti-citrulline antibodies) but were all negative.

Dr. Bonara (immunologist): The patient later presented with a new febrile episode. Given the negativity of all the infective investigations and assuming an autoimmune disorder, methylprednisolone dosage was increased $(40 \mathrm{mg}$ every $12 \mathrm{~h}$ ). There was then a gradual improvement of the patient's clinical conditions: no more fever, acute-phase protein normalization, progressive resolution of pleural effusions with normal oxygen saturation in air, and normalization of bone marrow function.

Dr. Pisano: After excluding infectious causes, cancer and the most common autoimmune diseases, the clinical presentation of our patient was suggestive of an adult's still disease (ASD).

Dr. Bonara (immunologist): You are right, this was our hypothesis.

\section{Diagnosis}

Dr. Gandolfi, Dr. Silini: How do you diagnose ASD?

Dr. Sinigaglia (rheumatologist): ASD is an inflammatory disease characterized by fever with daily peaks, evanescent rash and arthritis. There are no specific tests or test combinations that may be used to make a diagnosis. Diagnosis is mainly a diagnosis of exclusion. The criteria with greater sensitivity to make the diagnosis of ASD are the criteria of Yamaguchi (Table 1) [1-3].

Our patient had three major and three minor criteria; we also excluded other possible causes of disease.

Dr. Pisano: A key point to the diagnosis of ASD is the presence of ferritin values significantly above the normal limits (the ferritin level of our patient reached 14,000 $\mathrm{ng} / \mathrm{mL}$ ). It is reported that ferritin concentrations are markedly elevated in $70 \%$ of ASD cases. Serum ferritin values above $3,000 \mathrm{ng} / \mathrm{mL}$ in a patient with compatible symptoms should

Table 1 Yamaguchi criteria for classification of adult Still's disease

Presence of five or more criteria, of which at least two are major ( $96 \%$ sensitivity; $92 \%$ specificity)

Major criteria

Fever of at least $39^{\circ} \mathrm{C}$ lasting at least 1 week

Arthralgias or arthritis lasting 2 weeks or longer

A nonpruritic macular or maculopapular skin rash that is salmon-colored in appearance and usually found over the trunk or extremities during febrile episodes

Leukocytosis $(10,000 / \mu \mathrm{L}$ or greater), with at least $80 \%$ granulocytes

Minor criteria

Sore throat

Lymph node enlargement

Splenomegaly

Liver dysfunction (high AST/ALT)

Negative ANA, RF 
lead to the possibility of ASD in the absence of a bacterial or viral infection. This degree of hyperferritinemia is not observed with other rheumatic diseases, although it may be present in other hemophagocytic syndromes [4-6].

Dr. Gandolfi: Another useful element for the diagnosis of ASD would have been the levels of the glycosylated fraction of ferritin [7,8], because a reduction of this index is specific for ASD. The assay for this parameter was not available in our laboratories.

Dr. Pisano, Dr. Gandolfi, Dr. Silini: Our patient had no rash nor arthritis. How can this be explained?

Dr. Bonara: The classical rash of ASD is an evanescent, salmon-colored, macular or maculopapular eruption that tends to occur with fever. The rash predominantly involves the trunk and extremities, but can also involve the palms, soles, and occasionally the face. The Koebner phenomenon may be present, in which the cutaneous eruption can sometimes be elicited by rubbing the skin. Often, however, this rash occurs in the evening, and, because of its evanescence, is not detectable during the medical examination [9].

Arthritis is not mandatory in ADS; many patients, as our case, can have disabling myalgias.

Dr. Pisano, Dr. Gandolfi, Dr. Silini: Why did the patient present pancytopenia with severe anemia, associated with thrombocytopenia, and finally, after about 3 weeks of illness, leukopenia, while initially she had leukocytosis?

Dr. Bonara: The pancytopenia can be interpreted as the "macrophage activation syndrome", an acquired form of reactive hemophagocytic syndrome (RHS) that typically occurs in lupus or rheumatoid arthritis and also in ASD. It results from the aggressive proliferation of normal histiocytes and T-lymphocytes in various tissues. Hemophagocytosis of red cells (erythrophagocytosis), other white blood cells, or platelets in the bone marrow, spleen, or lymph nodes is the key diagnostic finding. RHS can occur at any times during the history of ASD; it occurs in a minority of patients, but may be underdiagnosed. Pleuritis, ARDS, and pancytopenia are more common in cases of ASD associated with RHS $[10,11]$.

Very interestingly, both ASD and RHS are now classified as "autoinflammatory diseases" [12], some clinical disorders marked by abnormally increased inflammation, mostly genetically determined. They are mediated by the cells and the products of innate immunity (mononuclear cells, IL1, TNF,...) and they are the counterpart of classical autoimmune diseases (like SLE) which are principally mediated by the cells and the products of acquired immunity ( $\mathrm{T}$ and $\mathrm{B}$ cells, antibodies, IL2,...). Under this new category are contained many heterogeneous disorders, like hereditary recurrent fevers, type two diabetes mellitus, Crohn disease or atherosclerosis, that are unified by the loss of regulatory mechanisms of inflammatory response.

I think that the comprehension of the clinical consequences of this disregulation could represent one of the most important advances of the last decade.

\section{Therapy}

Dr. Bonara: How do we manage ASD?

Dr. Silini: Therapeutic decisions should be based upon the extent and severity of organ system involvement. The principal options for treatment are NSAIDs, glucocorticoids, and other immunosuppressive drugs, biologic agents, and disease-modifying anti-rheumatic drugs (DMARDs). As a general approach, we suggest starting treatment with NSAID, but move quickly to glucocorticoids, followed by biologic agents if the ASD does not come under control [13].

Majority of patients eventually require treatment with glucocorticoids, and those with high fever, debilitating joint symptoms, or internal organ involvement (as our patient) should be treated with glucocorticoids from the outset of therapy. The usual prednisone dose is $0.5-1 \mathrm{mg} / \mathrm{kg} / \mathrm{day}$, but pulse methylprednisolone (e.g., 1,000 mg/daily for 3 days) can be used for life-threatening disease due to severe hepatic involvement, cardiac tamponade, disseminate intravascular coagulation, or other complications, followed by standard dose. To help keep steroid therapy lower, another immunosuppressor, e.g. methotrexate can be associated [14].

Other drugs that have been used in the treatment of ASD are biologic agents, like monoclonal antibodies against TNF, IL-2, CD-20 [15].

Dr. Bonara: In our case, we chose to give cyclosporine, because it is less harmful to the bone marrow (already compromised in our patient), and the first choice for the hemophagocytic syndrome. The typical cyclosporine regimen for this indication is $3-5 \mathrm{mg} / \mathrm{kg} / \mathrm{day}$, split into two doses [16].

Dr. Pisano, Dr. Gandolfi, Dr. Silini: What was the clinical response of the patient?

Dr. Bonara: The first treatment trial with corticosteroids was commenced employing methylprednisolone $20 \mathrm{mg}$ (equal to prednisone $0.5 \mathrm{mg} / \mathrm{kg}$ ). This dose proved to be ineffective to control the disease, probably because the RHS ensued. Once the hypothesis of ASD was formulated, the dose was increased to $1 \mathrm{mg} / \mathrm{kg}$ but with unsatisfactory results. We obtained a good clinical response with $2 \mathrm{mg} / \mathrm{kg}$ 
Table 2 Blood tests at admission and discharge

\begin{tabular}{lll}
\hline & Admission & Discharge \\
\hline $\mathrm{Hb}(\mathrm{g} / \mathrm{dL})$ & 8.1 & 10.9 \\
WBCs $($ cells/ $\mu \mathrm{L})$ & 14,100 & 12,100 \\
PLT (cells/ $\mu \mathrm{L})$ & 360,000 & 480,000 \\
Fibrinogen $(\mathrm{mg} / \mathrm{dL})$ & 300 & 256 \\
D-dimer $(\mathrm{ng} / \mathrm{dL})$ & 22,000 & 570 \\
CRP $(\mathrm{mg} / \mathrm{dL})$ & 16.8 & 0.5 \\
Procalcitonin $(\mathrm{ng} / \mathrm{mL})$ & 3.5 & 0.04 \\
Ferritin $(\mathrm{ng} / \mathrm{mL})$ & 12,868 & 493 \\
AST $(\mathrm{U} / \mathrm{L})$ & 63 & 11 \\
ALT $(\mathrm{U} / \mathrm{L})$ & 67 & 19 \\
CHE $(\mathrm{U} / \mathrm{L})$ & 2,418 & 5,942 \\
Albumin $(\mathrm{g} / \mathrm{dL})$ & 2.6 & 3.8 \\
LDH (U/L) & 828 & 281 \\
\hline
\end{tabular}

(methylprednisolone $40 \mathrm{mg}$ twice daily): the blood counts increased, fever resolved, inflammatory response improved, particularly ferritin levels (Table 2). Because of the severity of the clinical presentation and the coexistence of the RHS, we decided to associate treatment with cyclosporine.

Three months later, after tapering the prednisone, the patient is in excellent general condition, free from symptoms, and she has resumed work. The ferritin levels normalized; a modest sideropenic anemia persisted that was corrected with iron. There were no untoward side effects apart from a modest iatrogenic Cushing's syndrome.

Dr. Pisano, Dr. Gandolfi, Dr. Silini: To prevent side effects, the patient is taking a proton pump inhibitor and for osteoporosis prophylaxis, a bisphosphonate together with calcium and vitamin D. Renal function and cyclosporine concentrations are being monitored. How long does immunosuppressive therapy have to last?

Dr. Bonara: ASD is a bizarre disease; we do not have precise guide lines, but it is prudent to continue immunosuppressive therapy for many months maintaining a full dosage of cyclosporine and the minimal effective dose of corticosteroids. If there is good patient compliance, we will review the situation after 9 months of treatment evaluating the reappearance of symptoms and the markers of disease, in particular ferritin, acute-phase proteins, and the blood count.
Acknowledgments This case record was selected for the "Casi Clinici Gymnasium", session at the 2009 SIMI Annual Congress in Rome, and was reviewed by a Committee composed of Maria Domenica Cappellini, Nicola Montano and Luigi Pagliaro.

Conflict of interest None.

\section{References}

1. Yamaguchi M, Ohta A, Tsunematsu T et al (1992) Preliminary criteria for classification of adult Still's disease. J Rheumatol 19:424

2. Pouchot J, Sampalis JS, Beaudet F et al (1991) Adult onset Still's disease: manifestations, disease course and outcome in 62 patients. Medicine (Baltimore) 70:118

3. Masson C, Le Loet X, Liote F et al (1996) Comparative study of six types of criteria in adult Still's disease. J Rheumatol 23:495

4. Coffernils M, Soupart A, Pradier O et al (1992) Hyperferritinemia in adult onset Still's disease, the hemophagocytic syndrome. J Rheumatol 19:1425

5. Rogers JT, Lacroix L, Durmowitz G (1994) The role of cytokines in regulation of ferritin expression. Adv Exp Med Biol 356:127

6. Schwarz-Eywill M, Heilig B, Bauer H et al (1992) Evaluation of serum ferritin as a marker for adult Still's disease activity. Ann Rheum Dis 51:683

7. Vignes S, Le Moel G, Fautrel B et al (2000) Percentage of glycosylated serum ferritin remains low throughout the course of adult onset Still's disease. Ann Rheum Dis 59:347

8. Fautrel B, Le Moel G, Saint-Marcoux B et al (2001) Diagnostic value of ferritin and glycosylated ferritin in adult onset Still's disease. J Rheumatol 28:322

9. Elkon KB, Hughes GR, Bywaters EGL et al (1982) Adult onset Still's disease: twenty-year follow-up and further studies of patients with active disease. Arthritis Rheum 25:647

10. Arlet J-B, Huong DL, Marinho A et al (2006) Reactive haemophagocytic syndrome in adult-onset Still's disease: a report of six patients and a review of the literature. Ann Rheum Dis 65:1596

11. Kumakura S, Ishikura H, Munemasa $S$ et al (1997) Adult onset Still's disease associated hemophagocytosis. J Rheumatol 24:1645

12. Kastner DL, Aksentijevich I, Goldbach-Mansky R (2010) Autoinflammatory disease reloaded: a clinical perspective. Cell 140:784

13. Masson C, Le Loet X, Liote F et al (1995) Adult Still's disease. Part II. Management, outcome, and prognostic factors. Rev Rhum Engl Ed 62:758

14. Fautrel B, Borget C, Rozenberg S et al (1999) Corticosteroid sparing effect of low dose methotrexate treatment in adult Still's disease. J Rheumatol 26:373

15. Aarntzen EH, van Riel PL, Barrera P (2005) Refractory adult onset Still's disease and hypersensitivity to non-steroidal antiinflammatory drugs and cyclo-oxygenase- 2 inhibitors: are biological agents the solution? Ann Rheum Dis 64:1523

16. Shojania K, Chalmers A, Rangno K (1995) Cyclosporin A in the treatment of adult Still's disease. J Rheumatol 22:1391 